\title{
PENGARUH PEMBERIAN INSENTIF DAN MOTIVASI TERHADAP KINERJA KARYAWAN PT. FIFGROUP POS PAINAN
}

\author{
Piko Dharma Putra, Febsri Susanti \\ Sekolah Tinggi Ilmu Ekonomi "KBP" \\ febsrisusanti@akbpstie.ac.id \\ fiekodharma@yahoo.com
}

\begin{abstract}
The purpose of this study is to determine and analyze the influence of incentives and motivation on employee performance at PT. FIFGROUP Pos Painan. The sampling technique used was tottal sampling, while the number of samples used for the analysis was 35 people. Data analysis techniques used to test the hypothesis is multiple regression linear. In this study there are two independent variables, namely incentives and motivation. Variable incentives and motivations have no effect on employee performance at PT. FIFGROUP Pos Painan. While the value of determination coefficient in this study was found at 0.387 or equal to 38.7\%. These results show that employee performance at PT. FIFGROUP Pos Painan can be explained by incentives and work motivation of 38.7\%, while the remaining $61.3 \%$ allegedly explained by other factors not examined in this study, such as organizational culture, work discipline, and work stress. Based on the results of multiple linear regression analysis, it was found that the incentive and motivation variables positively affect employee performance at PT. FIFGROUP Pos Painan. This research provides practical recommendations for the management of PT. FIFGROUP Painan Post to continuously strive to improve employee performance in the future.
\end{abstract}

Keywords: Incentives, Motivation and Performance

\section{PENDAHULUAN}

Kinerja yang optimal adalah dambaan manajemen diseluruh organisasi, namun kinerja akan dapat dicapai apabila proses kerja yang dilaksanakan pada organisasi berjalan sesuai tugas pokok dan fungsinya. Hal ini dipengaruhi terhadap penerapan sistem timbal balik yang diterima karyawan dan motivasi karyawan didalam tujuan bergabung kepada organisasi.

Pemberian insentif kepada para karyawan pada dasarnya diharapkan akan memberikan motivasi kepada para karyawan yang mempunyai latar belakang yang berbeda, hal ini akan memberikan dampak yang positif didalam menjalankan tugas-tugasnya agar tetap semangat dan terhindar dari menurunnya produktivitas kerja karyawan dan berujung pada kinerja dan kelangsungan organisasi tersebut.

Motivasi yang ada pada diri karyawan berdampak positif bagi organisasi, hal ini bisa dipengaruhi oleh factor pendidikan, kepribadian maupun kebutuhannya 
masing-masing, dengan adanya pemberian insentif akan dapat mempersempit perbedaan tujuan karyawan sehingga dapat memotivasi pada diri pegawai agar bersemangat memberikan dedikasi yang tinggi terhadap organisasinya.

PT. FIFGROUP merupakan Grup Manajemen dari beberapa perusahaan yang memiliki unit bisnis yang berbeda beda. PT. FIFGROUP saat ini menaungi PT. Federal international finance dan PT. Astra Multi Finance. PT. FIFGROUP bergerak di bisnis layanan pembiayaan dengan nama merek Antara lain, Jasa layanan pembiayaan sepeda motor honda . baik motor baru maupun seken berkualitas disebut dengan FIFASTRA dan jasa layanan multi produk, mulai dari elektronik, perabot rumah tangga, peralatan komputer, furniture, sepeda sampai traktor tangan disebut dengan SPEKTRA. Jasa layanan pembiayaan ini meliputi metode pembiayaan konvensional maupun syariah.

PT. FIFgroup hadir untuk mengakomodir keanekaragaman kebutuhan masyarakat Indonesia dengan senantiasaberpegang pada prinsip inovasi dan kreativitas. Mengubah tantangan menjadi peluang adalah landasan pemikiran yang membuat PT. FIFGROUP terus berkembang.

Untuk mendukung pelaksanakan tugas karyawan di kantor PT. FIFGROUP Pos painan ini setiap karyawannya mendapatkan insentif. Adapun insentif atau tunjangan yang mereka dapatkan yaitu Tambahan Penghasilan karyawan. Insentif tersebut diberikan PT. FIFGROUP setempat yang jumlah per orangnya berbedabeda sesuai dengan Posisi dan terget yang di berikan kepada Masing masing karyawan tersebut. Hal tersebut dilakukan dengan harapan berpengaruh bagi kinerja setiap karyawan PT. FIFGROUP pos painan.

Insentif yang diberikan oleh PT. FIFGROUP untuk karyawan yang berkantor di painan sesuai dengan kelas jabatannya dapat memberikan dampak positif, dimana di satu sisi insentif memberikan dampak yang baik pada kinerja karyawan dan di sisi lain insentif diharapkan dapat memberikan motivasi kepada karyawan serta meningkatkan kinerja karyawan PT. FIFGROUP di pos painan supaya tujuan dan kebutuhan yang dinginkan tercapai.

Insentif adalah tambahan penghasilan berdasarkan beban kerja, tambahan penghasilan berdasarkan kondisi kerja, tambahan penghasilan berdasarkan tempat bertugas, tambahan penghasilan berdasarkan kelangkaan profesi, tambahan penghasilan berdasarkan kinerja, dan tambahan penghasilan berdasarkan pertimbangan objektif lainnya.

Berdasarkan observasi penulis di PT.FIFGROUP pos painan masih terdapat permasalahan-permasalahan dalam proses pekerjaan. Adapun masalahnya yaitu kedisiplinan Karyawan yang sering dating terlambat. Hal ini juga didukung oleh teori Singodimejo dalam Sutrisno (2009:86) mengatakan disiplin adalah sikap kesediaan dan kerelaan seseorang untuk mematuhi dan menaati norma-norma peraturan yang berlaku disekitarnya. Disiplin yang baik akan mempercepat tujuan pekerjaan diPerusahaan, sedangkan disiplin yang merosot akan menjadi penghalang dan memperlambat pencapaian tujuan pekerjaan di Perusahaan, sehingga akan menimbulkan suatu pelanggaran yang merugikan baik secara langsung maupun tidak langsung terhadap dirinya dan Perusahaan.

Salah satunya pelanggaran yang sering dilakukan Karyawan terhadap peraturan Perusahaan adalah mengenai tingkat kehadiran karyawan di kantor. 
Kenyataan yang terdapat dilapangan masih ada karyawan yang dating terlambat kekantor, karyawan tersebut juga sering menunda-nunda pekerjaan. Walaupun sering menunda-nunda pekerjaan, karyawan tersebut masih memberikan pelayanan yang baik terhadap custumer.

Rumusan Masalah

1. Bagaimana pengaruh pemberian insentif terhadap kinerja karyawan PT. FIFGROUP pos painan.

2. Bagaimana pengaruh motivasi terhadap kinerja karyawan PT. FIFGROUP pos painan.

Tujuan Penelitian

1. Pengaruh pemberian insentif terhadap kinerja karyawan PT. FIFGROUP pos painan

2. Pengaruh motivasi terhadap kinerja karyawan PT. FIFGROUP pos painan.

\section{LANDASAN TEORI \\ Kinerja Karyawan \\ Pengertian Kinerja}

Menurut Supardi (2013: 45) kinerja diartikan sebagai prestasi, menunjukkan suatu kegiatan atau perbuatan dan melaksanakan tugas yang telah dibebankan. Pengertian kinerja sering diidentikkan dengan prestasi kerja. Karena persamaan antara kinerja dengan prestasi kerja. Kinerja lebih sering disebut dengan prestasi yang merupakan 'hasil' atau 'apa yang keluar' (outcomes) dari sebuah pekerjaan dan kontribusi sumber daya manusia terhadap organisasi.

Menurut Hamzah dan Lamatenggo (2014: 60) mengemukakan bahwa "kinerja yang nyata jauh melampaui apa yang diharapakan adalah kinerja yang menetapkan standar-standar tertinggi orang itu sendiri, selalu standar-standar yang melampaui apa yang diminta atau diharapkan orang lain”.

\section{Pemberian Insentif}

\section{Pengertian Insentif}

Menurut Yuniarsih dan Suwatno (2008: 131) dalam Kadarisman (2012: 191) mengemuka kan bahwa "Insentif adalah penghargaan/ imbalan yang diberikan untuk memotivasi pekerja/ anggota organisasi agar motivasi dan produktivitas kerjanya tinggi, sifatnya tidak tetap atau sewaktu-waktu."

Menurut Wungu dan Brotoharsojo (2003: 101) dalam Kadarisman (2012: 195) mengemuka kan bahwa "insentif merupakan elemen penghasilan atau balas jasa yang diberikan secara tidak tetap atau bersifat variabel tergantung pada kondisi pencapaian prestasi kerja pegawai." Menurut Saydam (2000: 236)dalam Kadarisman (2012: 196) mengemukakan bahwa "insentif pada dasarnya adalah sebagai tambahan penghasilan yang diberikan kepada karyawan tertentu."

\section{Motivasi Kerja}

\section{Pengertian Motivasi}

Motivasi didalam pribadi orang, akan berpengaruh langsung terhadap tindakan yang akan dilakukannya, karena motivasi merupakan kekuatan yang ada dalam diri seseorang untuk berbuat sesuatu yang dapat memuaskan keinginannya. Menurut Robbins (2003: 156) dalam Wibowo (2012: 378) menyatakan bahwa 
"motivasi sebagai proses yang menyebabkan intensitas, arah, dan usaha terusmenerus individu menuju pencapaian tujuan".

Menurut Greenberg dan Baron (2003: 190) dalam Wibowo (2012: 379) menyatakan bahwa "motivasi merupakan serangkaian proses yang membangkitkan, mengarahkan, dan menjaga perilaku manusia menuju pada pencapaian tujuan.

\section{Hipotesis}

H1= Diduga Pemberian Insentifberpengaruhsignifikan dan positif Terhadap Kinerja karyawan PT. FIFGROUP pos painan.

$\mathrm{H} 2$ = Diduga motivasi berpengaruhsignifikan dan positif terhadap Kinerja karyawan PT. FIFGROUP pos painan.

\section{METODE PENELITIAN}

\section{Populasi dan Sampel}

Penulis menetapkan populasi sebagai sampel karena jumlahnya kurang dari 100. Maka populasi yang dijadikan sebagai sampel dalam penelitian ini berjumlah 35 orang karyawan PT. FIF GROUP Pos Painan sehingga penelitian ini tidak dilakukan sampling.

\section{Teknik Analisis Data}

\section{Analisis Regresi Linier Sederhana}

Uji regresi linear sederhana merupakan teknik statistik yang digunakan untuk menguji pengaruh variabel bebas terhadap variabel terikat (Sekaran, 2006:299). Persamaan regresi linier sederhana adalah:

Di mana:

$$
Y=\alpha+\beta_{1} X_{1}+\beta_{2} X_{2}
$$

$$
\begin{array}{ll}
\mathrm{Y} & =\text { Kinerja } \\
\alpha & =\text { Konstanta } \\
\beta & =\text { Koefisien Regresi } \\
\mathrm{X}_{1} & =\text { Pemberian Insentif } \\
\mathrm{X}_{2} & =\text { Motivasi Kerja }
\end{array}
$$

\section{Pengujian Hipotesis}

\section{Uji T-Statistik}

Uji t dilakukan untuk menguji apakah secara terpisah variabel independen mampu menjelaskan variabel dependen secara baik. Kriteria pengujian:

1) Jika $\mathrm{t}$ hitung $>\mathrm{t}$ tabel, maka $\mathrm{H}_{0}$ ditolak dan $\mathrm{H}_{1}$ diterima.

2) Jika t hitung < t tabel, maka $\mathrm{H}_{0}$ diterima dan $\mathrm{H}_{1}$ ditolak.

3) Tingkat kepercayaan $\alpha$ untuk pengujian hipotesis adalah $95 \%$ atau $\alpha=$ 0,05

\section{HASIL PENELITIAN DAN PEMBAHASAN}

\section{Hasil Analisis Regresi Berganda}

\section{Analisis Regresi Berganda}

Uji regresi linear berganda merupakan teknik statistik yang digunakan untuk menguji pengaruh beberapa variabel bebas terhadap variabel terikat (Sekaran, 2006). Hasil analisis regresi linier berganda dapat diringkas pada Tabel berikut ini: 
Tabel 1

Ringkasan Hasil Analisis Regresi Linier Berganda

\begin{tabular}{|c|l|r|r|c|}
\hline Variabel Terikat & \multicolumn{1}{|c|}{$\begin{array}{c}\text { Konstanta dan } \\
\text { Variabel Bebas }\end{array}$} & $\begin{array}{c}\text { Koefisien } \\
\text { Regresi }\end{array}$ & Signifikan & Keterangan \\
\hline \multirow{4}{*}{$\begin{array}{c}\text { Kinerja } \\
\text { Karyawan (Y) }\end{array}$} & Konstanta (a) & 0.663 & 0.566 & - \\
\cline { 2 - 6 } & Insentif (X1) & 0.760 & 0.080 & H1 Ditolak \\
\cline { 2 - 6 } & Motivasi (X2) & 0.251 & 0.338 & H2 Ditolak \\
\cline { 2 - 6 } & F & 11.738 & $0.000^{\mathrm{a}}$ & H3 Diterima \\
\cline { 2 - 6 } & R Square & \multicolumn{2}{|c|}{0.423} & \\
\hline
\end{tabular}

Sumber: Olahan Data SPSS, Tahun 2017.

Berdasarkan hasil analisis regresi linier berganda yang disajikan pada tabel diatas, berikut ini dapat dikemukakan persamaan regresi linier berganda:

$\mathrm{Y}=\mathrm{a}+\mathrm{b}_{1} \mathrm{X}_{1}+\mathrm{b}_{2} \mathrm{X}_{2}$

$\mathrm{Y}=0,663+0,760 \mathrm{X} 1+0,251 \mathrm{X} 2$

Koefisisen regresi masing-masing variabel penelitian dapat diartikan sebagai berikut:

1. Nilai konstanta sebesar 0,663 berarti tanpa adanya pengaruh dari variabel bebas maka nilai variabel terikat hanya sebesar 0,663 . Hal ini berarti bahwa apabila variabel bebas nilainya konstan (insentif dan motivasi), maka nilai variabel kinerja hanya sebesar 0,663 .

2. Besaran koefisien regresi variabel insentif bernilai positif bermakna jika variabel insentif mengalami kenaikan maka kinerja karyawan akan mengalami peningkatan. Koefisien bernilai positif artinya terjadi hubungan positif antara insentif dengan kinerja karyawan, semakin tinggi insentif maka kinerja karyawan akan semakin baik. Besaran koefisien regresi variabel insentif adalah 0,760 satuan. Hal ini bermakna bahwa jika terjadi peningkatan insentif sebesar satu satuan dengan asumsi variabel motivasi kerja tetap, maka akan meningkatkan kinerja karyawan sebesar 0,760 satuan.

3. Besaran koefisien regresi variabel motivasi kerja bernilai positif bermakna jika variabel motivasi kerja mengalami kenaikan maka kinerja karyawan akan mengalami peningkatan. Koefisien bernilai positif artinya terjadi hubungan positif antara motivasi kerja dengan kinerja karyawan, semakin baik motivasi kerja maka kinerja karyawan akan semakin baik. Besaran koefisien regresi variabel motivasi kerja adalah 0,251 satuan. Hal ini bermakna bahwa jika terjadi peningkatan motivasi kerja sebesar satu satuan dengan asumsi variabel insentif tetap, maka akan meningkatkan kinerja karyawan sebesar 0,251 satuan.

\section{Uji Koefisien Determinasi}

Koefisien determinasi yang digunakan adalah nilai $R$ Square karena lebih dapat dipercaya dalam mengevaluasi model regresi. Dari proses pengujian koefisien determinasi yang telah dilakukan diperoleh ringkasan hasil seperti yang terlihat pada Tabel berikut ini: 
Tabel 2

Hasil Pengujian Koefisien Determinasi

Model Summary

\begin{tabular}{|l|c|r|r|r|r|}
\hline Model & $\mathrm{R}$ & $\mathrm{R}$ Square & Adjusted R Square & Std. Error of the Estimate & Durbin-Watson \\
\hline 1 & $.651^{\mathrm{a}}$ & .423 & .387 & .73610 & 2.757 \\
\hline
\end{tabular}

a. Predictors: (Constant), Motivasi Kerja, insentif

b. Dependent Variable:

Kinerja

Sumber: Olahan Data SPSS 2017.

Dari hasil olahan data yang dapat dilihat pada Tabel 2, diketahui bahwa dari pengujian Koefisien Determinasi terlihat nilai R square adalah sebesar 0,387 atau sama dengan $38,7 \%$. Hasil tersebut memperlihatkan bahwa kinerja karyawan pada PT. FIFGROUP Pos Painan yang dapat dijelaskan oleh insentif dan motivasi kerja sebesar $38,7 \%$, sedangkan sisanya $61,3 \%$ diduga dijelaskan oleh faktorfaktor lain yang tidak diteliti dalam penelitian ini, seperti budaya organisasi, disiplin kerja, dan stress kerja.

\section{PEMBAHASAN}

\section{Pengaruh Insentif Terhadap Kinerja Karyawan}

Berdasarkan hasil pengolahan data terlihat bahwa koefisien regresi variabel insentif memiliki arah positif yaitu sebesar 0,760 dan memiliki nilai signifikansi sebesar 0,080 tahapan pengujian dilakukan dengan menggunakan tingkat kesalahan sebesar 5\% (0,05), dengan demikian terlihat bahwa nilai signifikansi 0,080 lebih besarl dari alpha 0,05, maka keputusannya adalah Ho di terima dan Ha ditolak. Jadi dapat disimpulkan bahwa insentif tidak berpengaruh terhadap kinerja karyawan pada PT. FIFGROUP Pos Painan.

Hal ini memberikan kesimpulan bahwa dengan insentif maka karyawan akan terus mencoba untuk lebih baik lagi dalam bekerja baik itu untuk karyawan sendiri maupun bagi perusahaan, mengingat adanya balas jasa dalam bentuk insentif yang diberikan perusahaan sesuai dengan hasil dan prestasi kerja yang dicapai.

Pemberian insentif merupakan salah satu hal pokok yang harus diperhatikan oleh perusahaan. Semangat tidaknya karyawan bisa juga disebabkan oleh besar kecilnya insentif yang diterima. Apabila karyawan tidak mendapatkan insentif yang sesuai dengan besarnya pengorbanan dalam bekerja, maka karyawan tersebut cenderung malas bekerja dan tidak bersemangat yang ada akhirnya mereka bekerja semaunya tanpa ada kepuasan kerja yang memadai, yaitu sebagaimana diharapkan oleh karyawan tersebut.

Tujuan sebuah perusahaan untuk mencari keuntungan sebesar-besarnya secara efektif dan efisien dan mampu menjaga eksistensinya tanpa banyak mengalami hambatan. Sebagai lanagkah untuk mencapai tujuan tersebut, perusahaan harus menetapkan kebijakan-kebijakan yang sesuai dengan kondisi 
perusahaan. Salah satu wujud kebijakan yang harus diperhatikan oleh perusahaan adalah mengenai insentif. Insentif merupakan bagian dari kompensasi yang mengaitkan antara kinerja dengan bayaran. Insentif yang bervariasi baik yang bersifat finansial, maupun non finansial sangat baik diterapkan di dalam perusahaan, sebab insentif dapat memberikan rangsangan atau motivasi bagi karyawan untuk meningkatkan kinerja agar lebih baik.

Hasil penelitian ini tidak sejalan dengan hasil penelitian terdahulu yang dilakukan oleh Lia Mayangsari (2013) dengan judul penelitian Pengaruh Pemberian Insentif Terhadap Kinerja Karyawan Di Departemen Penjualan Pt. Pusri. Dimana hasil penelitian menyatakan bahwa insentif berpengaruh signifikan dan positif secara bersama-sama terhadap kinerja karyawan.

\section{Pengaruh Motivasi Kerja Terhadap Kinerja Karyawan}

Berdasarkan hasil pengolahan data terlihat bahwa koefisien regresi variabel motivasi kerja memiliki arah positif yaitu sebesar 0,251 dan memiliki nilai signifikansi sebesar 0,338 tahapan pengujian dilakukan dengan menggunakan tingkat kesalahan sebesar 5\% $(0,05)$, dengan demikian terlihat bahwa nilai signifikansi 0,338 lebih besar dari alpha 0,05, maka keputusannya adalah Ho di terima dan Ha ditolak. Jadi dapat disimpulkan bahwa motivasi kerja tidak berpengaruh terhadap kinerja karyawan pada PT. FIFGROUP Pos Painan.

Motivasi terbentuk dari sikap dalam menghadapi situasi kerja merupakan energi yang menggerakkan diri mereka yang bertujuan mencapai tujuan organisasi. Sikap yang positif terhadap situasi kerja itulah yang memperkuat motivasi kerjanya untuk mencapai kinerja maksimal. Bila seseorang pegawai di kantor PT. FIFGROUP Pos Painan termotivasi maka akan berupaya sekuat tenaga untuk mencapai tujuan, namun belum tentu upaya yang tinggi akan menghasilkan kinerja yang tinggi. Oleh karena itu, diperlukan intensitas dan kualitas dari upaya tersebut serta difokuskan pada tujuan organisasi. Kondisi internal yang menimbulkan dorongan, dimana kebutuhan yang tidak terpuaskan akan menimbulkan tegangan yang merangsang dorongan dari dalam diri individu. Dorongan ini menimbulkan perilaku pencarian untuk menemukan tujuan, tertentu.

Apabila ternyata terjadi pemenuhan kebutuhan, maka akan terjadi pengurangan tegangan. Pada dasarnya, karyawan yang termotivasi berada dalam kondisi tegang dan berupaya mengurangi ketegangan dengan mengeluarkan upaya. Proses motivasi yang menunjukkan kebutuhan yang tidak terpuaskan akan meningkatkan tegangan dan memberikan dorongan pada seseorang dan menimbulkan perilaku. Di Kantor PT. FIFGROUP Pos Painan tanpa ada motivasi sukar untuk berhasil, pegawai dalam tugas melaksanakan tugas membantu perusahaan memerlukan motivasi baik dari faktor eksternal maupun internal. Motivasi pegawai di Kantor PT. FIFGROUP Pos Painan dalam bekerja dapat berupa intensitas (kesungguhan dan ketekkunan) yang tinggi dalam melaksanakan tugas.

Hasil penelitian ini tidak sejalan dengan hasil penelitian terdahulu yang dilakukan oleh Sismona (2014) dengan judul penelitian Pengaruh Motivasi Kerja Dan Kemampuan Kerja Terhadap Kinerja Pegawai Pada Dinas Kependudukan Dan Pencatatan Sipil Kabupaten Pasaman Barat. Dimana hasil penelitian 
menyatakan motivasi kerja dan kemampuan kerja berpengaruh signifikan terhadap kinerja pegawai.

\section{SIMPULAN}

1. Insentif memiliki nilai signifikansi sebesar 0,080 , nilai signifikan tersebut lebih besar dari alpha 0,05. Hal ini dapat diartikan bahwa insentif tidak berpengaruh terhadap kinerja karyawan pada PT. FIFGROUP Pos Painan. Berdasarkan hasil pengolahan data dapat diketahui bahwa rerata variabel insentif adalah 4,44 dengan TCR sebesar $88,8 \%$. Hal ini bermakna bahwa insentif termasuk ke dalam kategori baik.

2. Motivasi kerja memiliki nilai signifikansi sebesar 0,338 , nilai signifikan tersebut lebih besar dari alpha 0,05 . Hal ini dapat diartikan bahwa motivasi kerja tidak berpengaruh terhadap kinerja karyawan pada PT. FIFGROUP Pos Painan. Berdasarkan hasil pengolahan data dapat diketahui bahwa rerata variabel motivasi kerja adalah 4,18 dengan TCR sebesar 83,6\%. Hal ini bermakna bahwa motivasi kerja termasuk ke dalam kategori baik.

3. Insentif dan motivasi kerja berpengaruh signifikan secara bersama-sama terhadap kinerja karyawan pada PT. FIFGROUP Pos Painan.

4. Dari hasil olahan data diketahui bahwa dari pengujian Koefisien Determinasi terlihat nilai $\mathrm{R}$ square adalah sebesar 0,387 atau sama dengan $38,7 \%$. Hasil tersebut memperlihatkan bahwa kinerja karyawan pada PT. FIFGROUP Pos Painan yang dapat dijelaskan oleh insentif dan motivasi kerja sebesar 38,7\%, sedangkan sisanya $61,3 \%$ diduga dijelaskan oleh faktor-faktor lain yang tidak diteliti dalam penelitian ini, seperti budaya organisasi, disiplin kerja, dan stress kerja.

5. Dari analisis regresi linier berganda, ditemukan bahwa insentif dan motivasi kerja berpengaruh positif terhadap kinerja karyawan pada PT. FIFGROUP Pos Painan.

\section{DAFTAR PUSTAKA}

Arikunto, Suharsimi. 2010. Prosedur Penelitian. Jakarta: Rineka Cipta.

Aziz, N. (2019). Pengaruh Lingkungan Kerja Terhadap Kinerja Yang Dimediasi Oleh Motivasi Kerja Karyawan Rocky Plaza Hotel Padang. https://doi.org/10.17605/OSF.IO/E4C59

Sutrisno, Edy. 2009. Sumber Daya Manusia. Jakarta: Kencana Prenada Media Group.

Ghozali, Imam. 2011. Aplikasi Analisis Multivariate dengan Program SPSS. Semarang: Badan Penerbit Universitas Diponegoro.

Hamzah, \& Lamatenggo, Nina. Teori Kinerja dan Pengukurannya. Jakarta: PT Bumi Aksara. 
Hasibuan, S.P. Malayu. 2009. Manajemen Sumber Daya Manusia. Jakarta: PT. Bumi Aksara.

Hasibuan, S.P. Malayu. 2007. Mananjemen: Dasar, Pengertian, Masalah. Jakarta: PT. Bumi Aksara.

I Wayan, Keto Gen. 2007. Pengaruh Kepemimpinan Dan Finansial Insentif Terhadap Motivasi Kerja Karyawan Di PT Cahaya Surya Bali Indah Divisi Hino Di Denpasar. Skripsi Universitas Warmadewa. Denpasar.

Junaidi, R., \& Susanti, F. (2019). Pengaruh Gaya Kepemimpinan Dan Budaya Organisasi Terhadap Kinerja Pegawai Pada UPTD Baltekkomdik Dinas Pendidikan Provinsi Sumatera Barat. https://doi.org/10.31227/osf.io/bzq75

Kadarisma, M. 2012. Manajemen Kompensasi. Jakarta: PT RajaGrafindo Persada.

Maulana, Malik Ibrahim. 2012 Pengaruh Gaji Dan Iinsentif Terhadap Produktivitas Kerja Karyawan Pada CV. Indo Perkasa Computindo Situbondo. Skripsi Universitas Islam Negeri. Malang.

Mayangsari, Lia. 2013. Pengaruh Pemberian Insentif Terhadap Kinerja Karyawan Di Departemen Penjualan Pt. Pusri. Skripsi Universitas Sriwijaya. Palembang.

Mayliza, R. (2019). Pengaruh Kompensasi Finansial, Lingkungan Kerja Dan Motivasi Kerja Terhadap Kinerja Pegawai Pada Kantor PDAM Kota Payakumbuh. https://doi.org/10.17605/OSF.IO/DZXAF

Nawawi. 2003. Metode Penelitian Bidang Sosial. Yogyakarta. Gajah Mada.

Prawirosentono, Suryadi 2008. Kebijakan Kinerja Karyawan. Yogyakarta: BPFE.

Riduwan. 2006. Belajar Mudah Penelitian. Bandung: Alfabeta.

Sardiman. 2011. Interaksi Dan Motivasi Belajar Mengajar. Jakarta: PT Raja Grafindo Persada

Sarwoto. 2000. Dasar-dasar Organisasi dan Manajemen. Jakarta: Ghalia Indonesia.

Siagian, Sondang P. 2009. Manajemen Sumber Daya Manusia. Jakarta: PT Bumi Aksara.

Simamora. 2002. Panduan Riset Perilaku Konsumen. Surabaya: Pustaka. Utama. 
Siregar, Syopian. 2011. Statistika Deskripsif. Jakarta: Raja Wali.

Sismona. 2014. Pengaruh Motivasi Kerja Dan Kemampuan Kerja Terhadap Kinerja Pegawai Pada Dinas Dinas Kependudukan Dan Pencatatan Sipil Kabupaten Pasaman Barat. Skripsi Sekolah Tinggi Keguruan Dan Ilmu Pendidikan PGRI Sumbar. Padang

Suliyanto. 2011. Ekonometrika Terapan (Teori dan Aplikasi dengan SPSS). Yogyakarta : Andi

Supardi. 2013. Kinerja Guru. Jakarta : $\quad$ PT Raja Grafindo Persada.

Wibowo. 2012. Manajemen Kinerja. Jakarta. PT Raja Grafindo Persada.

Widarjono. 2007. Ekonometrika Teori dan Aplikasi untuk Ekonomi dan Bisnis. Yogyakarta: Fakultas Ekonomi UI.

Wirawan. 2009. Evaluasi Kinerja Sumber Daya Manusia. Jakarta. Salemba Empat.

Yudistira, D. S., \& Susanti, F. (2019). Pengaruh Motivasi Kerja Dan Budaya Kerja Terhadap Kinerja Karyawan Dinas Pemberdayaan Masyarakat Dan Desa, Pengendalian Penduduk Dan Keluarga Berencana Kabupaten Pesisir Selatan. https://doi.org/10.31227/osf.io/jk54m 